\title{
Model-Based Water Wall Fault Detection and Diagnosis of FBC Boiler Using Strong Tracking Filter
}

\author{
Li Sun, Junyi Dong, Donghai Li, and Yuqiong Zhang \\ State Key Lab of Power System, Department of Thermal Engineering, Tsinghua University, Beijing 100083, China \\ Correspondence should be addressed to Donghai Li; lidongh@mail.tsinghua.edu.cn
}

Received 21 February 2014; Accepted 17 March 2014; Published 28 April 2014

Academic Editor: Zhijun Zhang

Copyright ( 2014 Li Sun et al. This is an open access article distributed under the Creative Commons Attribution License, which permits unrestricted use, distribution, and reproduction in any medium, provided the original work is properly cited.

\begin{abstract}
Fluidized bed combustion (FBC) boilers have received increasing attention in recent decades. The erosion issue on the water wall is one of the most common and serious faults for FBC boilers. Unlike direct measurement of tube thickness used by ultrasonic methods, the wastage of water wall is reconsidered equally as the variation of the overall heat transfer coefficient in the furnace. In this paper, a model-based approach is presented to estimate internal states and heat transfer coefficient dually from the noisy measurable outputs. The estimated parameter is compared with the normal value. Then the modified Bayesian algorithm is adopted for fault detection and diagnosis (FDD). The simulation results demonstrate that the approach is feasible and effective.
\end{abstract}

\section{Introduction}

Fluidized bed combustion (FBC) boiler, the most popular clean coal combustion technology in power and chemical industries [1], facilitates burning a wide variety of fuels with high combustion efficiency, especially for the low-grading coal. The technology burns fuel at temperatures from 800 to $950^{\circ} \mathrm{C}$, a range where nitrogen oxide $\left(\mathrm{NO}_{x}\right)$ formation is much lower than that in traditional pulverized coal boiler [2]. The fluidized bed has several potential advantages in $\mathrm{CO}_{2}$ capture from flue gas [3]. In addition, water-wall slagging is significantly eliminated due to the combustion condition of lower temperature. Furthermore, soot formation can be attenuated with the appropriate distributor plate layout. However, wastage of tube materials, both refractory and metallic, is more prominent than pulverized coal boiler because the particulates in the fluidization state strike and rub the tube more fiercely and frequently. It has become a source of concern for FBC boilers because it is responsible for waterwall burst and even undesired shutdowns.

A great deal of research has been done in an effort to further understand metal wastage in fluidized bed combustion environments and to find solutions to ease it. It is generally acknowledged that tube wastage is caused by simultaneous corrosion and erosion. In $[4,5]$, the erosion-prone areas were identified in circulating and bubbling fluidized bed boilers and described current methods for erosion protection. The wastage rate was most significant in the water wall around the bed region, decreasing with increasing height [6]. The rate of tube erosion is usually a complex function of characteristics of the coal particulates, that is, shape, strength, size, composition, and ash content, such as $\mathrm{SiO}_{2}, \mathrm{Al}_{2} \mathrm{O}_{3}$ and $\mathrm{Fe}_{2} \mathrm{O}_{3}$ [7]. Most researches [4-8] of tube wear have been conducted for exploration of erosion mechanism to improve boiler design. However, there have been few reports on online monitoring of erosion occurring during runtime. In [9], the method by ultrasonic thickness gauge was introduced to investigate tube wastage patterns successfully. But the increased equipment cost and integration difficulties limit its broad application in industry.

An alternative monitoring method based on boiler dynamic model and optimal estimation theory was introduced in this paper. By delving into the performance characteristics of FBC boiler, we can deduce that the global wastage or deposition rate of water wall could be expressed equally as the variation of the overall heat transfer coefficient regardless of its cause. Hence the problem of thickness measurement and detection was reconstructed as a parameter 
estimation issue. This critical parameter can be assumed as an extended state, which would be estimated with other state variables simultaneously in an augmented nonlinear model. Specifically, the observability of augmented system should be examined, which serves as a necessary precondition of the proposed software redundancy method other than hardwarebased measurement method.

The conventional linear estimation theory was proposed by Kalman [10] and then developed into nonlinear version in NASA, named "extended Kalman filter" (EKF) which was widely applied in the aerospace and navigation areas. However, in most industrial cases, the EKF method is of poor robustness against model mismatches [11], which can only give a biased state estimation and even may quickly diverge, owing to its linearization. We propose to adopt a new filter, called a strong tracking filter (STF) [12], which can overcome the above-mentioned flaws of EKF. In STF, the mean square of estimated residues is minimized based on the orthogonality principal. Thus the Kalman gain can be adjusted in real time to track the actual states. This approach is applicable to joint states and parameters estimation with unknown changing laws.

In the current paper, Section 2 is devoted to a brief introduction to the structure and model of a bubbling fluidized bed combustor. The outline of STF is presented in Section 3. After introducing an FDD strategy based on modified Bayes' classification algorithm, computer simulation results are given in Section 4 to show the effectiveness of the proposed approach. Section 5 is the conclusions and future work. The strategy in this paper is also applicable for circulating fluidized bed (CFB) boiler if the corresponding dynamic model can be provided with acceptable accuracy.

\section{System Description and Analysis of FBC Boiler}

2.1. Overview of Fluidized Bed Combustion Technology. Fluidized beds find widespread application in industrial applications because of their favorable heat transfer properties. With appropriate upward-blowing primary air velocity to suspend solid fuels, there are tumbling action and bubble formation, which provides more effective combustion and heat transfer. The bed of solid particles exhibits the properties of a boiling liquid and assumes the appearance of a fluid- "bubbling fluidized bed." The schematic of a FBC boiler is shown in Figure 1.

As shown in Figure 1, a mixture of inert/sorbent bed material and solid fuel is fluidized by the primary air entering from below. Secondary air is injected above the fuel bed to ensure complete gas burning out. But the total amount should be limited due to economic efficiency. The heat released in combustion is captured by heat exchangers and used for the generation of steam.

2.2. Global Dynamic Model of Bubbling FBC Boiler. The fullorder dynamic model of FBC has been set up for mechanism study, but it is not suitable for fault detection and state estimation because of the complexity. The classical bubbling

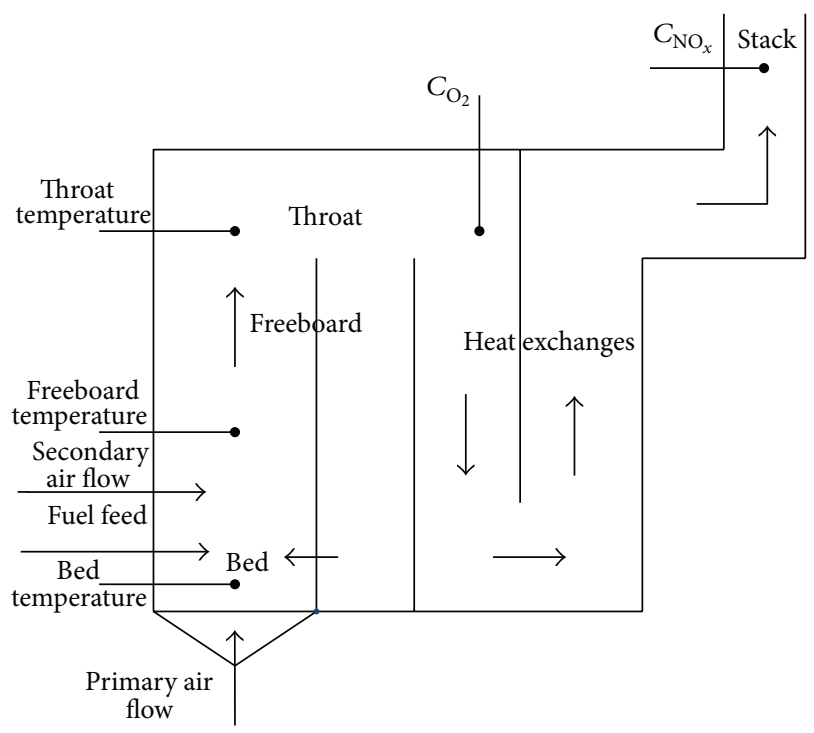

Figure 1: A schematic of a typical FBC plant.

FBC model was originally formulated in [13] based on mass and energy balances, which was verified by experimental data. To strike a balance between fidelity and simplicity, the model was further modified as follows [14].

Dynamics of fuel inventory $W_{C}[\mathrm{~kg}]$ :

$$
\frac{d W_{C}(t)}{d t}=(1-V) Q_{C}(t)-Q_{B}(t)
$$

Dynamics of bed oxygen content $C_{B}\left[\mathrm{Nm}^{3} / \mathrm{Nm}^{3}\right]$ :

$$
\frac{d C_{B}(t)}{d t}=\frac{1}{V_{B}}\left[C_{1} F_{1}(t)-Q_{B}(t) X_{C}-C_{B}(t) F_{1}(t)\right] .
$$

Dynamics of freeboard oxygen content $C_{F}\left[\mathrm{Nm}^{3} / \mathrm{Nm}^{3}\right]$ :

$$
\begin{aligned}
\frac{d C_{F}(t)}{d(t)}=\frac{1}{V_{F}}\{ & C_{B}(t) F_{1}(t)+C_{2} F_{2}(t) \\
& \left.\quad-V Q_{C}(t) X_{V}-C_{F}(t)\left[F_{1}(t)+F_{2}(t)\right]\right\} .
\end{aligned}
$$

Dynamics of bed temperature $T_{B}[\mathrm{~K}]$ :

$$
\begin{aligned}
\frac{d T_{B}(t)}{d t}=\frac{1}{C_{I} W_{I}}\{ & H_{C} Q_{B}(t)+c_{1} F_{1}(t) T_{1} \\
& \left.\quad-\alpha_{B t} A_{B t}\left[T_{B}(t)-T_{B t}\right]-c_{F} F_{1}(t) T_{B}(t)\right\} .
\end{aligned}
$$

Dynamics of freeboard temperature $T_{F}[\mathrm{~K}]$ :

$$
\begin{aligned}
\frac{d T_{F}(t)}{d t}=\frac{1}{C_{F} V_{F}}\{ & V Q_{C}(t)+c_{1} F_{1}(t) T_{1} \\
& \left.\quad-\alpha_{B t} A_{B t}\left[T_{B}(t)-T_{B t}\right]-c_{F} F_{1}(t) T_{B}(t)\right\} .
\end{aligned}
$$


Dynamics of thermal power $P[\mathrm{MW}]$ :

$$
\frac{d P(t)}{d t}=\frac{1}{\tau_{\operatorname{mix}}}\left[P_{C}(t)-P(t)\right]
$$

where the combustion rate in bed $Q_{B}[\mathrm{~kg} / \mathrm{s}]$ is $Q_{B}(t)=$ $\left(W_{C}(t) / t_{C}\right)\left(C_{B}(t) / C_{1}\right)$ and the combustion power $P_{C}[\mathrm{MW}]$ is $P_{C}(t)=10^{-6}\left[H_{C} Q_{B}(t)+H_{V} V Q_{C}(t)\right]$. Here, other detailed variable nomenclatures and fine-tuned model parameter values have been given in [14]. In this FBC process, the manipulated inputs $\mathbf{u}$ are fuel feed $Q_{C}[\mathrm{~kg} / \mathrm{s}]$, primary air flow $F_{1}\left[\mathrm{Nm}^{3} / \mathrm{s}\right]$, and secondary air flow $F_{2}\left[\mathrm{Nm}^{3} / \mathrm{s}\right]$; the controlled variables are power $P$, bed temperature $T_{B}$, and freeboard oxygen content $C_{F}$; freeboard temperature $T_{F}$ is also a measurable output in addition to the 3 controlled variables. Hereby a canonical nonlinear model can be established from (1)-(6):

$$
\begin{gathered}
\dot{\mathbf{x}}=f(\mathbf{x}, \mathbf{u}), \\
\mathbf{y}=h(\mathbf{x}),
\end{gathered}
$$

where $\mathbf{x}=\left[W_{C} C_{B} C_{F} T_{B} T_{F} P\right]^{T}, \mathbf{u}=\left[Q_{C} F_{1} F_{2}\right]^{T}$, and $\mathbf{y}=\left[\begin{array}{llll}T_{B} & P & T_{F} & C_{F}\end{array}\right]^{T}$.

\section{Strong Tracking Filter Based State Estimation}

3.1. Extension and Discretization. If soot formation or erosion occurs in water wall tube, the corresponding heat transfer coefficient will change due to variation of thermal conduction resistance. However, it is impossible to obtain the heat transfer coefficient $h_{B}$ by measurement. We can estimate the variation of $h_{B}$ by using methods based on joint state and parameter estimation. Considering the influence of noise, and assuming $h_{B}$ as an extended state, the augmented model can be discretized as

$$
\begin{gathered}
\mathbf{z}(k+1)=f_{e}(\mathbf{z}(k), \mathbf{u}(k))+\mathbf{w}_{k}, \\
\mathbf{y}(k+1)=h_{e}(\mathbf{z}(k+1))+\mathbf{v}_{k+1},
\end{gathered}
$$

where $\mathbf{z}(k)=\left[\mathbf{x}(k) h_{B}(k)\right]^{T}$ is the augmented state by assuming $h_{B}(k+1)=h_{B}(k)$. Thereby, functions $f_{e}$ and $h_{e}$ can be derived from (7) by Euler methods. $\mathbf{w}_{k}$ and $\mathbf{v}_{k}$ are the process and observation noises which are both assumed to be zero mean multivariate Gaussian noises with covariances $Q_{k}$ and $R_{k}$, respectively.

3.2. Basic Principals of STF. It is well known that the extended Kalman filter (EKF) can be used [15] for the joint estimation of the systems described by (8), which can be summarized as the following formulas.

Predicted state:

$$
\widehat{\mathbf{z}}_{k}^{-}=f_{e}\left(\widehat{\mathbf{z}}_{k-1}^{+}, \mathbf{u}_{k-1}\right) .
$$

Predicted covariance:

$$
P_{k}^{-}=F_{k-1} P_{k-1}^{+} F_{k-1}^{T}+Q_{k-1} .
$$

Measurement residual:

$$
\gamma_{k}=\mathbf{y}_{k}-h_{e}\left(\widehat{\mathbf{z}}_{k}^{-}\right) .
$$

Kalman gain:

$$
K_{k}=P_{k}^{-} H_{k}^{T}\left(H_{k} P_{k}^{-} H_{k}^{T}+R_{k}\right)^{-1} .
$$

Updated state:

$$
\widehat{\mathbf{z}}_{k}^{+}=\widehat{\mathbf{z}}_{k}^{-}+K_{k} \gamma_{k}
$$

Updated covariance:

$$
P_{k}^{+}=\left(I-K_{k} H_{k}\right) P_{k}^{-},
$$

where the superscripts - and + represent the values before and after measurement correction, respectively. $F_{k}$ and $H_{k}$ are the state transition and observation matrices by linearizing $f_{e}$ and $h_{e}$ at each time step.

However, in most cases, especially for industrial fault diagnostics, the EKF has the following flaws:

(i) poor robustness against model mismatches;

(ii) sensitivity to the statistics of the initial states and noise;

(iii) weak tracking ability to the suddenly changing states.

All these drawbacks will be more prominent especially when filter approaches steady, as shown in the next subsection. The essential reason accounting for the phenomenon is that the optimal Kalman gain is actually calculated by open-loop method in spite of updating process in state correction. According to the original paper [10] regarding linear filtering, the predicted covariance and Kalman gain both depend on the model and initial parameter settings of $P_{0}, Q_{k}$, and $R_{k}$. The Kalman gain $K_{k}$ will approach zero after long-time steadiness and then EKF will lose tracking ability when process uncertainty occurs.

For this reason, Zhou and Frank proposed a strong tracking filter (STF) in [12]. By introducing a diagonal matrix $\Lambda_{k}$ to $(10)$,

$$
P_{k}^{-}=\Lambda_{k} F_{k-1} P_{k-1}^{+} F_{k-1}^{T}+Q_{k-1}
$$

the Kalman gain can be adjusted online to maintain the strong tracking ability of filters. The suboptimal fading factors $\Lambda_{k}$ can be obtained recursively by solving the following equations:

$$
\begin{aligned}
& E\left[\left(\mathbf{z}_{k+1}-\widehat{\mathbf{z}}_{k+1}^{+}\right)^{T}\left(\mathbf{z}_{k+1}-\widehat{\mathbf{z}}_{k+1}^{+}\right)\right]=\min , \\
& E\left[\boldsymbol{\gamma}_{k+1}^{T} \boldsymbol{\gamma}_{k+1+j}\right]=0 ; \quad j=1,2, \ldots
\end{aligned}
$$

The second equation of (16) is named orthogonality principle, whose physical meaning is that the residual error series should be made mutually orthogonal at each step, so that the rich information in the residual error series could be extracted. For deduction details, see [12]. 


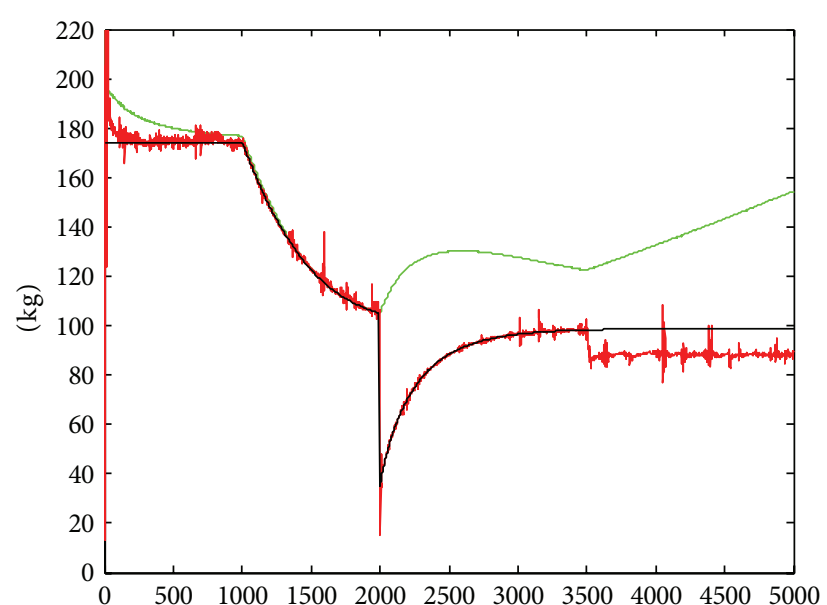

(s)

(a) Fuel inventory $[\mathrm{kg}]$

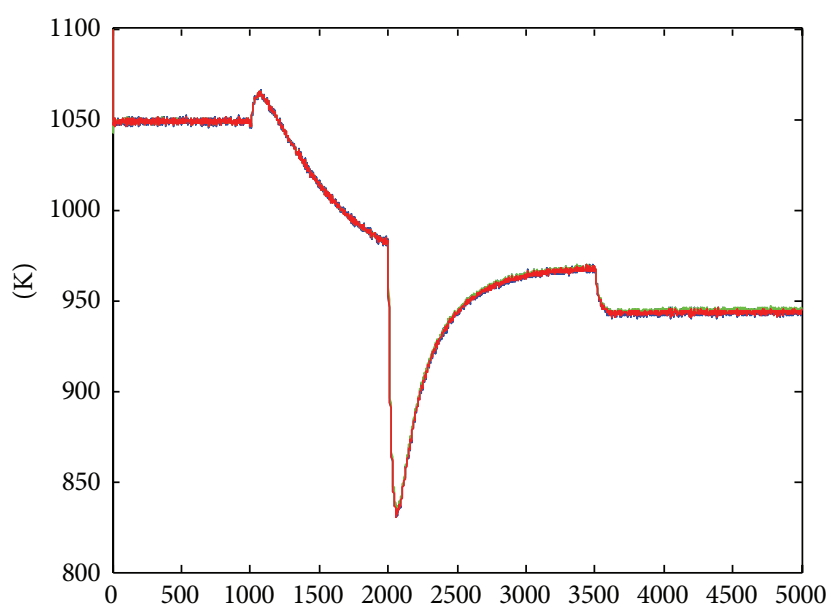

(s)

(c) Bed temperature $[\mathrm{K}]$

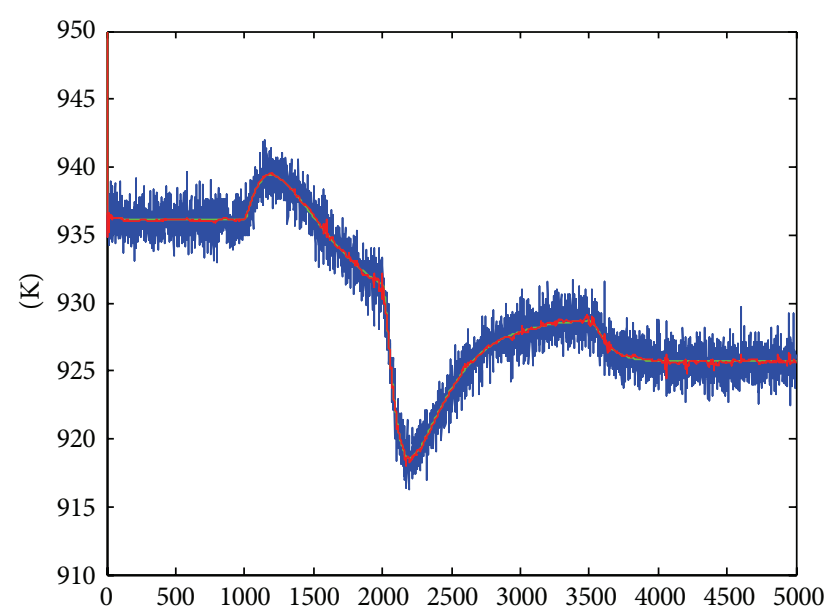

(s)

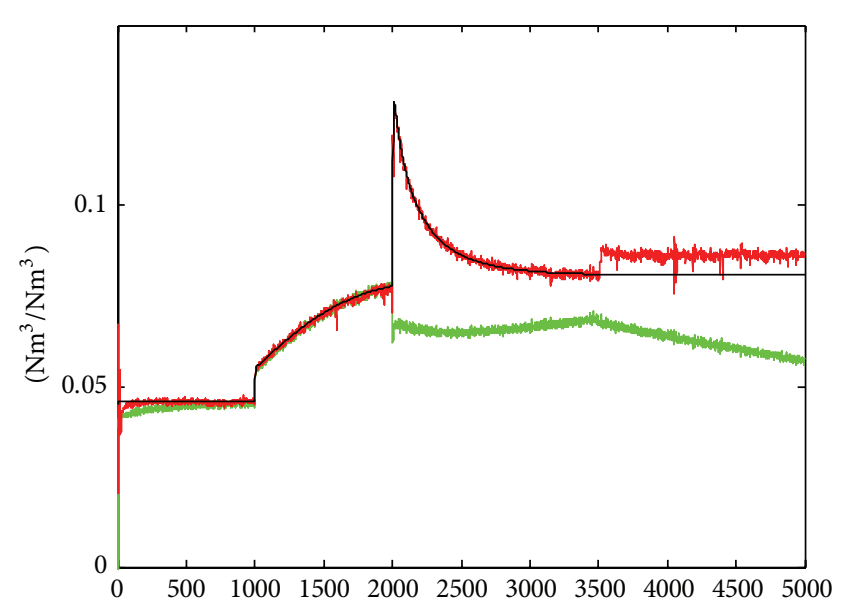

(s)

(b) Bed $\mathrm{O}_{2}$ content $\left[\mathrm{Nm}^{3} / \mathrm{Nm}^{3}\right]$

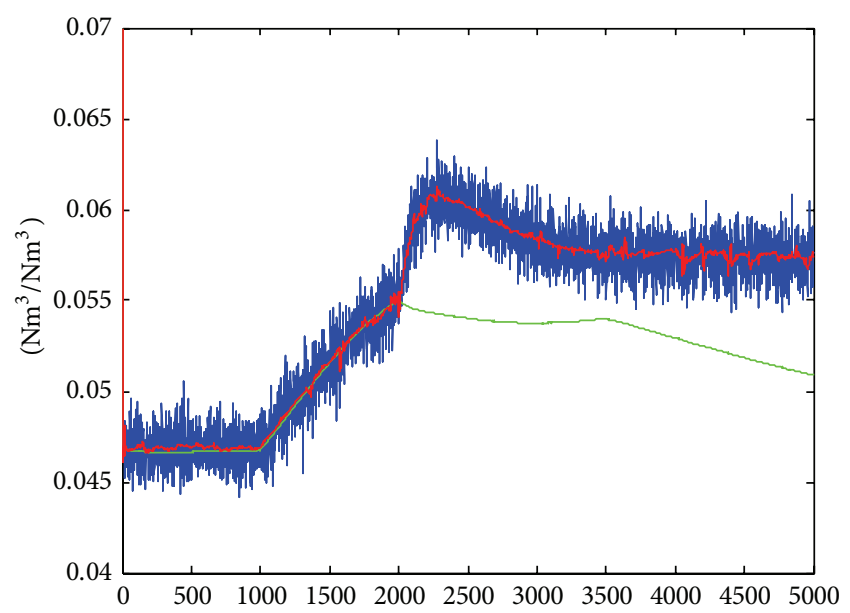

(s)

(d) Freeboard $\mathrm{O}_{2}$ content $\left[\mathrm{Nm}^{3} / \mathrm{Nm}^{3}\right]$

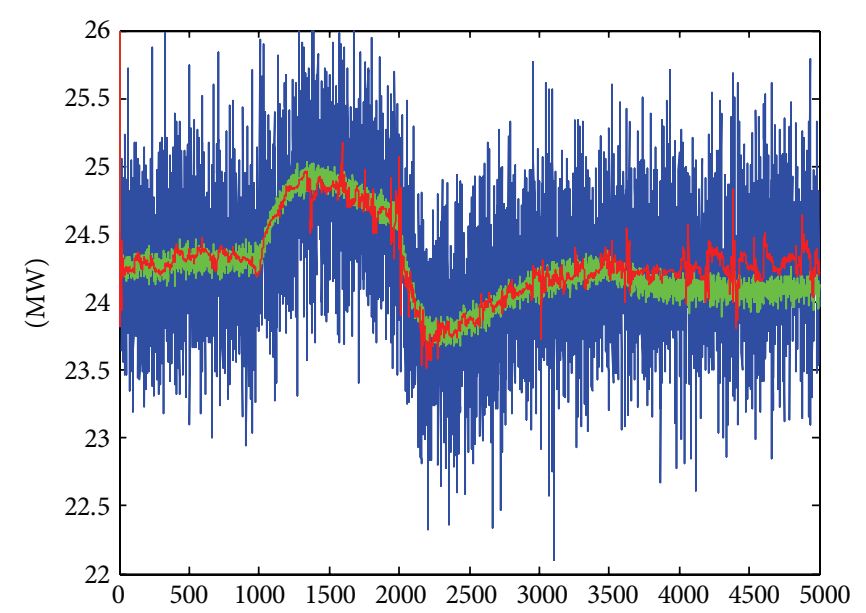

(s)

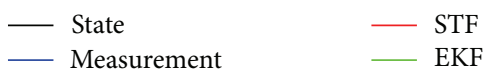

(f) Thermal power $[\mathrm{MW}]$

(e) Freeboard temperature [K]

Figure 2: Simulation comparison of estimated states. 


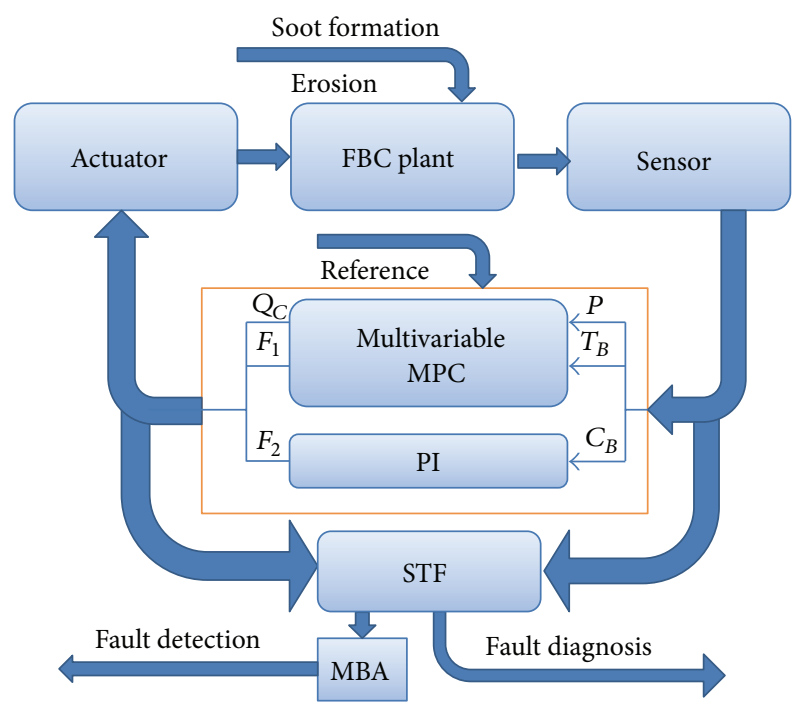

FIGURE 3: The structure of closed-loop fault detection and diagnosis.

3.3. Open-Loop Simulation and Comparison. In this part, an open-loop simulation on FBC plant (7) was conducted without joint estimation. In the simulation, EKF and STF shared the same set of filter parameters with initial states deviating from the actual value. The simulation results are shown in Figure 2. In simulating process, the input variable (fuel feed $Q_{C}$ ) increased by $25 \%$ at $t=1000 \mathrm{~s}$; the state variable (fuel inventory $W_{C}$ ) dropped suddenly at $t=2000 \mathrm{~s}$. In addition, there is a mutation in heat transfer coefficient $h_{B}$ at $t=3500 \mathrm{~s}$.

As shown in Figure 2, the adjective "strong" in STF implies (i) faster rate of convergence in the presence of initial error (see Figure 2(a)), (ii) stronger tracking ability to the abrupt changing states regardless of dynamic or stationary fashion, and (iii) better robustness to modeling error (Figures 2(c), 2(d), and 2(e), titles: "freeboard" and "temperature").

\section{FDD of Water Wall}

4.1. Strategy of Fault Detection. Once the erosion or soot formation occurs, it will grow more and more serious. Hence, it is necessary to detect the fault in time. Assume the fault is a drift-type process. While the boiler is running at normal state, the heat transfer parameter is

$$
h_{B}(k) \sim N\left(h_{B}^{0}, \sigma_{0}^{2}\right),
$$

where $h_{B}^{0}$ is the normal operating value and $\sigma_{0}^{2}$ is the reasonable variation which is acceptable for engineering. The modified Bayes' algorithm is adopted for fault detection.

Define

$$
\begin{gathered}
\mu_{h_{B}}(k)=\frac{1}{N} \sum_{j=1}^{N} \widehat{h}_{B}^{+}(k-j), \\
\sigma_{h_{B} 1}^{2}(k)=\frac{1}{N-1} \sum_{j=1}^{N}\left[\widehat{h}_{B}^{+}(k-j)-h_{B}^{0}\right]^{2},
\end{gathered}
$$

$$
\begin{gathered}
\sigma_{h_{B} 2}^{2}(k)=\frac{1}{N-1} \sum_{j=1}^{N}\left[\widehat{h}_{B}^{+}(k-j)-\mu_{h_{B}}(k)\right]^{2}, \\
d(k)=\frac{\sigma_{h_{B} 1}^{2}(k)}{\sigma_{0}^{2}}-\ln \frac{\sigma_{h_{B} 2}^{2}(k)}{\sigma_{0}^{2}}-1,
\end{gathered}
$$

where $N$ is the preselected data window and $d$ is named detection parameter. When the boiler operates well, $d$ is close to zero. As soon as the fault occurs, $d$ will be soaring sensitively. When a threshold $\beta_{0}$ is defined, the strategy of fault detection is, thus, obtained:

$$
d(k)>\beta_{0}
$$

where $\beta_{0}$ can be selected by operating experience. With smaller $\beta_{0}$, smaller faults can be detected, but more false alarms occur. On the other hand, with larger $\beta_{0}$, only relative larger fault can be detected, and missing alarms will increase.

4.2. Closed-Loop Structure of Fault Diagnosis. In [16], the authors proposed a multivariable coordinated control method of FBC boiler based on LSSVM-GPC, which can control output power and bed temperature well by regulating fuel feed and primary air flow. Here, a PI controller was applied in the secondary air flow-freeboard oxygen content loop. Based on the above discussion, a closed-loop fault detection and diagnosis strategy was developed under the control framework, as shown in Figure 3, where the strong tracking filter was used to estimate state variables and heat transfer coefficient dually based on (8).

4.3. Numerical Simulation. The simulation time is 14000 s. A load-up command was given with setpoints of $P$ and $T_{B}$ rising to $30 \mathrm{MW}$ and $850^{\circ} \mathrm{C}$, respectively, while the setpoint of $C_{B}$ was kept constant.

Suppose soot was deposited gradually in water wall at $t=2000 \mathrm{~s}$ and then was cleaned up by soot blower at $t=7000 \mathrm{~s}$. After 1000 seconds, tube erosion of water wall occurred due to severe attrition. Let $\Lambda_{k}=\lambda_{k} I_{7}$; that is, the STF based on multiple fading factors deteriorates to a single fading factor which also has good tracking ability. The closedloop simulation results were shown in Figures 4-6.

It can be seen from Figure 4 that STF can track all the state variables with almost no errors under the condition of joint estimation while EKF is more sensitive to model mismatch (see Figures 4(a) and 4(b)). Figure 5(a) shows the overwhelming superiority of STF in tracking time-varying heat transfer coefficient with unknown changing laws while the EKF can be used to estimate constant parameters only. Figure 5(b) shows that the fading factor $\lambda_{k}$ can be increased rapidly once model mismatch happens. Thus the Kalman gain can be adjusted in real time, which accounts for the strong tracking ability essentially.

As shown in Figure 6, the detection parameter $d$ is hypersensitive to water wall fault, which grows exponentially once fault happens. The incipient fault can be detected at an early stage. For example, the soot formation fault is detected at 


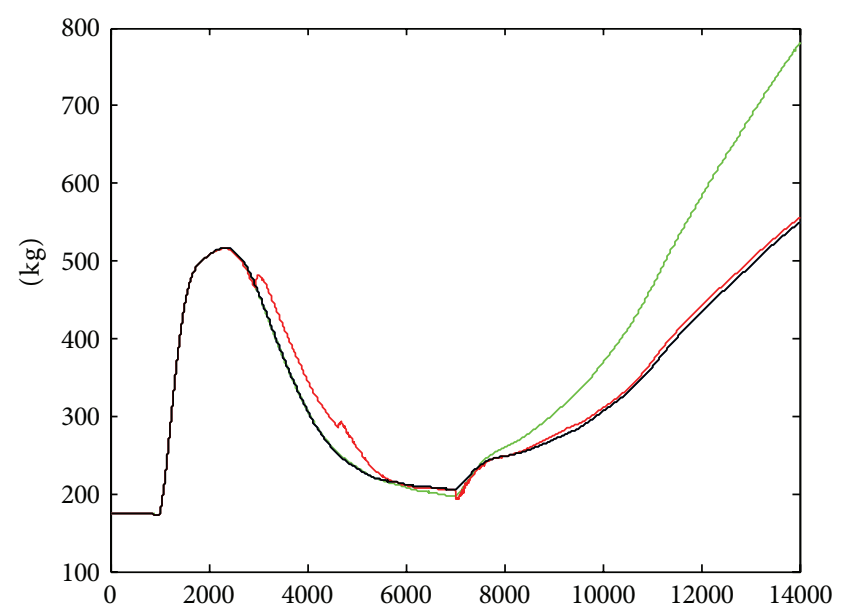

(s)

(a) Fuel inventory $[\mathrm{kg}]$

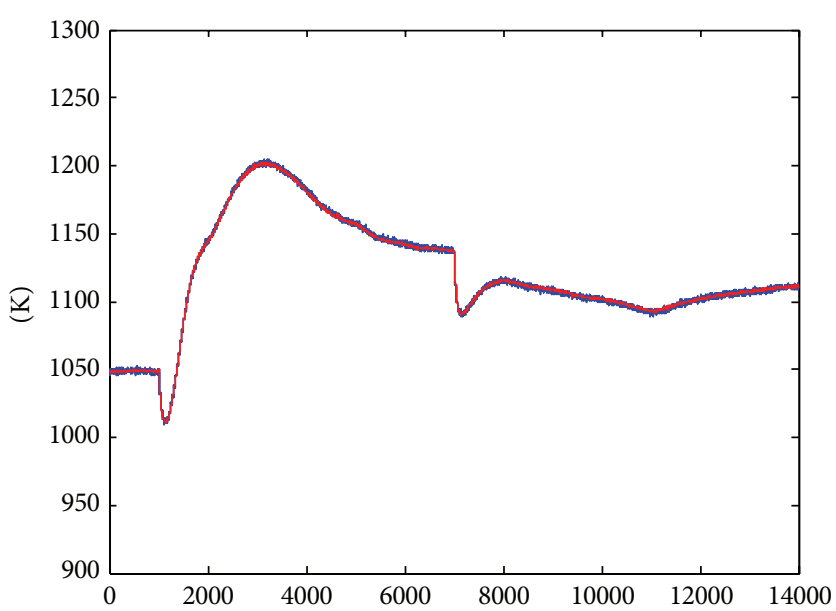

(s)

(c) Bed temperature $[\mathrm{K}]$

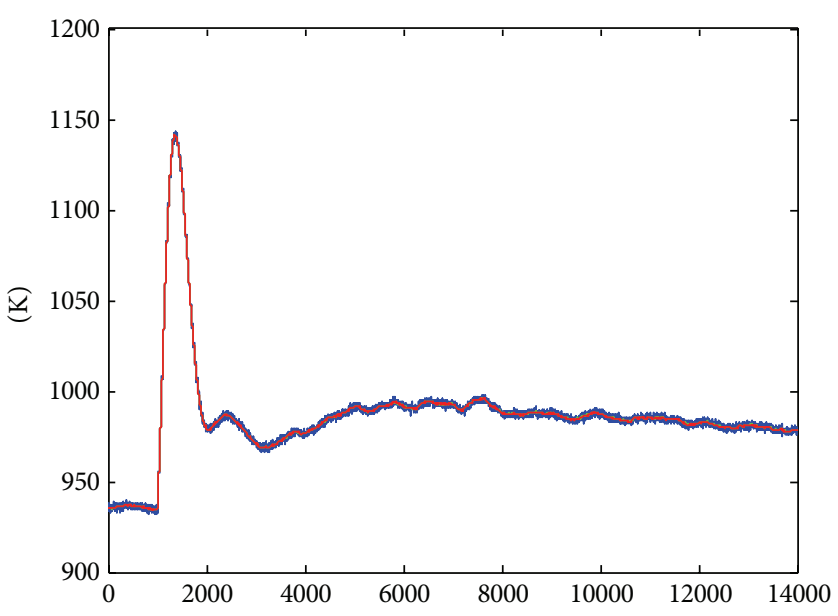

(s)

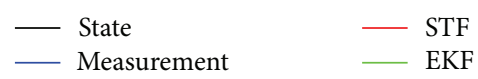

(e) Freeboard temperature [K]

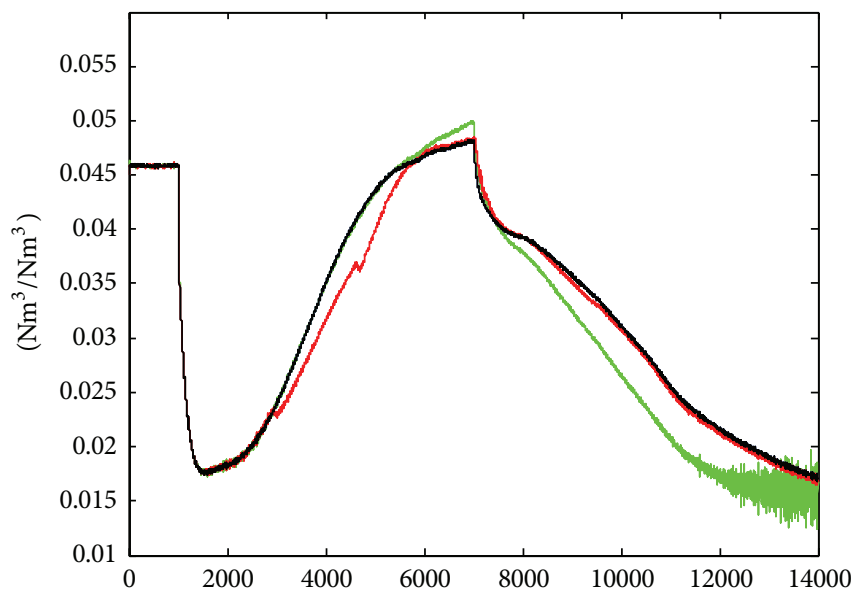

(s)

(b) Bed $\mathrm{O}_{2}$ content $\left[\mathrm{Nm}^{3} / \mathrm{Nm}^{3}\right]$

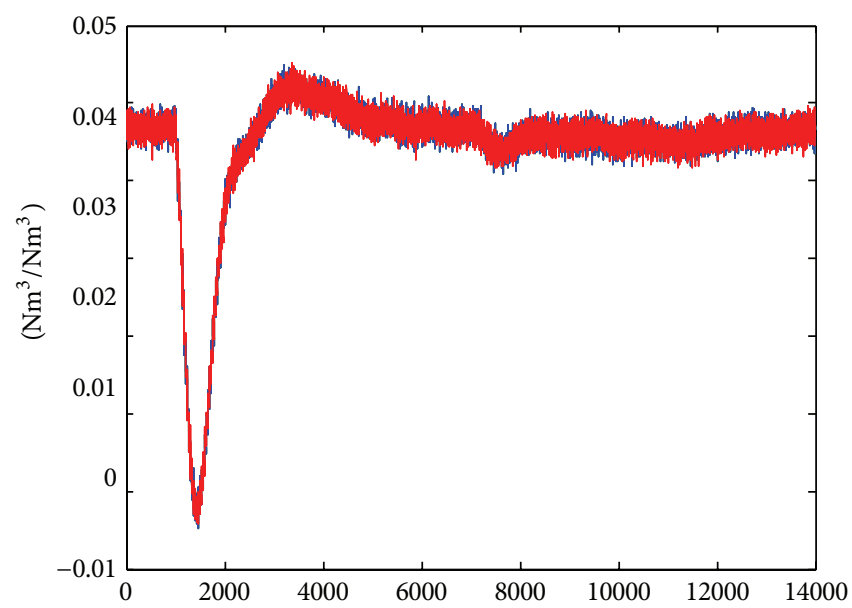

(s)

(d) Freeboard $\mathrm{O}_{2}$ content $\left[\mathrm{Nm}^{3} / \mathrm{Nm}^{3}\right]$

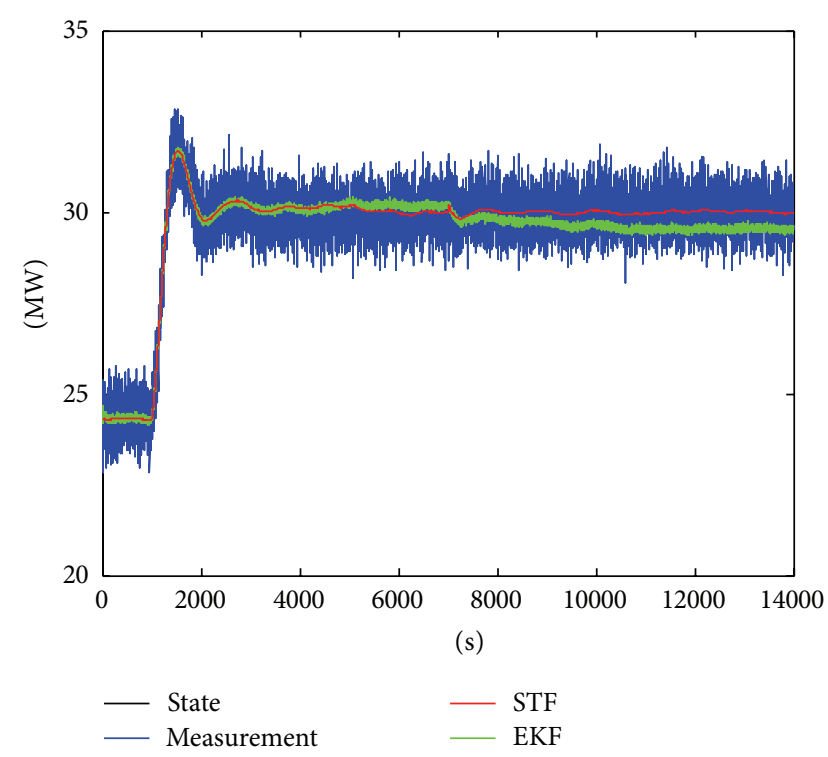

(f) Thermal power [MW]

FIGURE 4: States estimation of closed-loop simulation. 


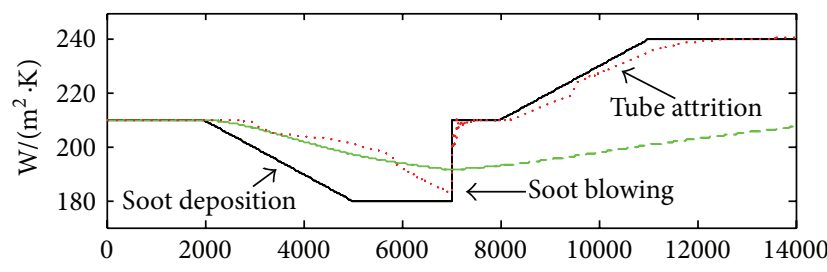

(s)

- Actual
-- EKF
… STF

(a) Heat transfer coefficient estimation $\left[\mathrm{W} /\left(\mathrm{m}^{2} \cdot \mathrm{K}\right)\right]$

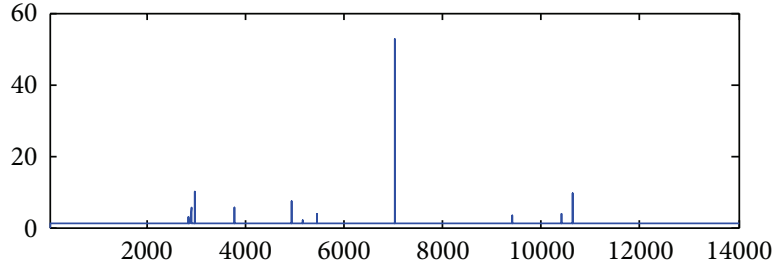

(s)

(b) Fading factor

Figure 5: Heat transfer coefficient estimation.

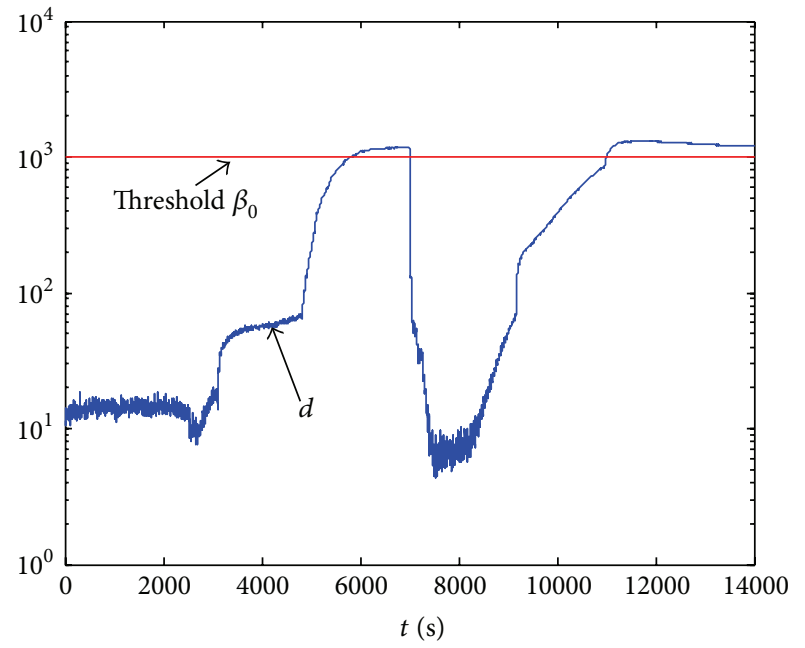

FIGURE 6: A semilog graph of detection parameter $d$.

$t=5493 \mathrm{~s}$ with estimated fault amplitude, -19.9 . The erosion fault is detected at $t=10006 \mathrm{~s}$ with estimated fault amplitude, 19.8 (see Figure 5(a)). The estimation accuracy of the fault amplitude is $66.4 \%$ and $99.3 \%$, respectively. It is possible to detect a fault earlier if we select a lower threshold, but the rate of false alarm will correspondingly increase.

\section{Conclusion and Future Work}

Because the security and reliability of FBC boiler are becoming more and more important, and the erosion is one of the most common faults of FBC boiler, it is urgent to investigate further the erosion fault of FBC. The STF is adopted for joint estimation due to the virtue of strong robustness against model mismatch and strong tracking of drifting states, as well as jumping states even when the filter is stable. According to the estimated heat transfer coefficient, the soot formation and erosion can be detected based on the modified Bayes' algorithm. At last, the simulation results demonstrate that the approach is feasible and effective. The line of research will lead to the future work in comprehensive fault detection and diagnosis and fault-tolerant control by incorporating other common faults, such as sensor and actuator faults.

\section{Conflict of Interests}

The authors declare that there is no conflict of interests regarding the publication of this paper.

\section{Acknowledgment}

This work has been supported by the National Natural Science Foundation of China (nos. 51176086 and 51076071).

\section{References}

[1] L. F. de Diego, M. de Las Obras-Loscertales, A. Rufas, F. GarciaLabiano, and P. Gayan, "Pollutant emissions in a bubbling fluidized bed combustor working in oxy-fuel operating conditions: effect of flue gas recirculation," Applied Energy, vol. 102, pp. 860867,2013

[2] R. Leimbach, "Intelligent control of FBC boilers," POWER, vol. 156, pp. 48-51, 2012.

[3] J. Choi, C. Yi, S. Jo, H. Ryu, and Y. Park, "Simulation of a bubbling fluidized bed process for capturing $\mathrm{CO}_{2}$ from flue gas," Korean Journal of Chemical Engineering, pp. 1-7, 2013.

[4] J. Stringer and J. Stallings, "Materials issues in circulating fluidized-bed combustors," in Proceedings of the 11th International Conference on Fluidized Bed Combustion, vol. 2, pp. 589608, ASME, New York, NY, USA, April 1991.

[5] N. G. Solomon, "Erosion-resistant coatings for fluidized bed boilers," Materials Performance, vol. 37, no. 2, pp. 38-43, 1998.

[6] T.-W. Kim, J.-H. Choi, D. W. Shun et al., "Wastage rate of water walls in a commercial circulating fluidized bed combustor," The Canadian Journal of Chemical Engineering, vol. 84, no. 6, pp. 680-687, 2006.

[7] B.-Q. Wang and K. Luer, "The relative erosivity of limestone, dolomite and coal samples from an operating boiler," Wear, vol. 215, no. 1-2, pp. 180-190, 1998.

[8] Z. Nawaz, T. Xiaoping, X. Wei, and F. Wei, "Attrition behavior of fine particles in a fluidized bed with bimodal particles: influence of particle density and size ratio," Korean Journal of Chemical Engineering, vol. 27, no. 5, pp. 1606-1612, 2010.

[9] T.-W. Kim, J.-H. Choi, D. W. Shun, S.-S. Kim, S. D. Kim, and J. R. Grace, "Wear of water walls in a commercial circulating 
fluidized bed combustor with two gas exits," Powder Technology, vol. 178, no. 3, pp. 143-150, 2007.

[10] R. E. Kalman, "A new approach to linear filtering and prediction problems," Journal of Basic Engineering, vol. 82, pp. 35-45, 1960.

[11] L. Ljung, "Asymptotic behavior of the extended Kalman filter as a parameter estimator for linear systems," IEEE Transactions on Automatic Control, vol. 24, no. 1, pp. 36-50, 1979.

[12] D. H. Zhou and P. M. Frank, "Strong tracking filtering of nonlinear time-varying stochastic systems with coloured noise: application to parameter estimation and empirical robustness analysis," International Journal of Control, vol. 65, no. 2, pp. 295307, 1996.

[13] E. Ikonen and U. Kortela, "Dynamic model for a bubbling fluidized bed coal combustor," Control Engineering Practice, vol. 2, no. 6, pp. 1001-1006, 1994.

[14] E. Ikonen and K. Najim, Advanced Process Identification and Control, Marcel Dekker, New York, NY, USA, 2002.

[15] A. Yoo, T. C. Lee, and D. R. Yang, "Experimental simultaneous state and parameter identification of a $\mathrm{pH}$ neutralization process based on an Extended Kalman Filter," Korean Journal of Chemical Engineering, vol. 21, no. 4, pp. 753-760, 2004.

[16] L. Sun, L. Pan, and J. Shen, "A multivariable coordinated control method of FBC boiler based on LSSVM-GPC," Journal of Southeast University, vol. 2, pp. 312-316, 2013. 


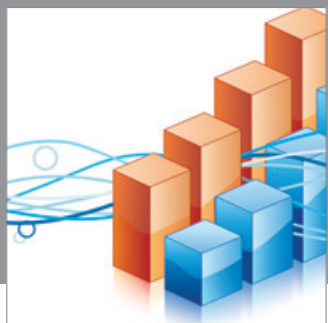

Advances in

Operations Research

mansans

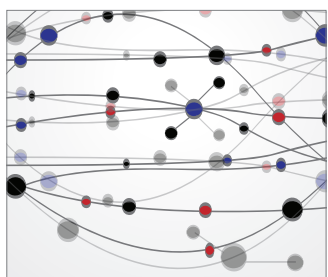

The Scientific World Journal
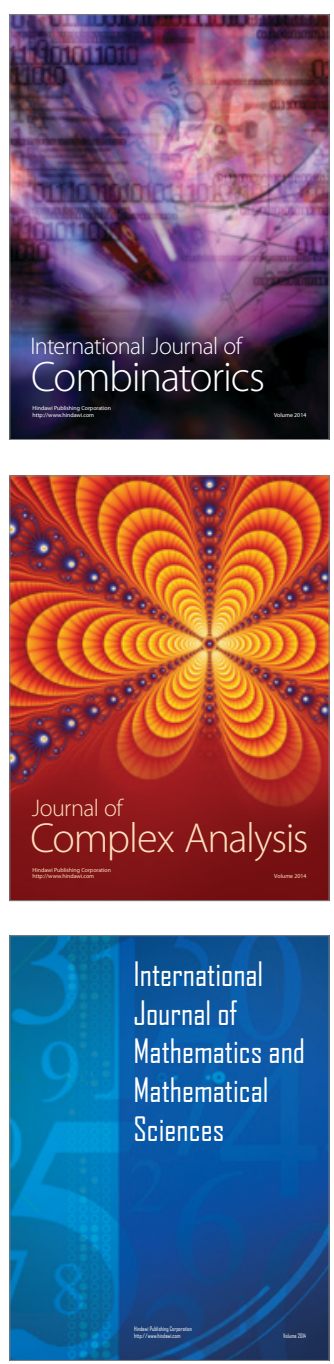
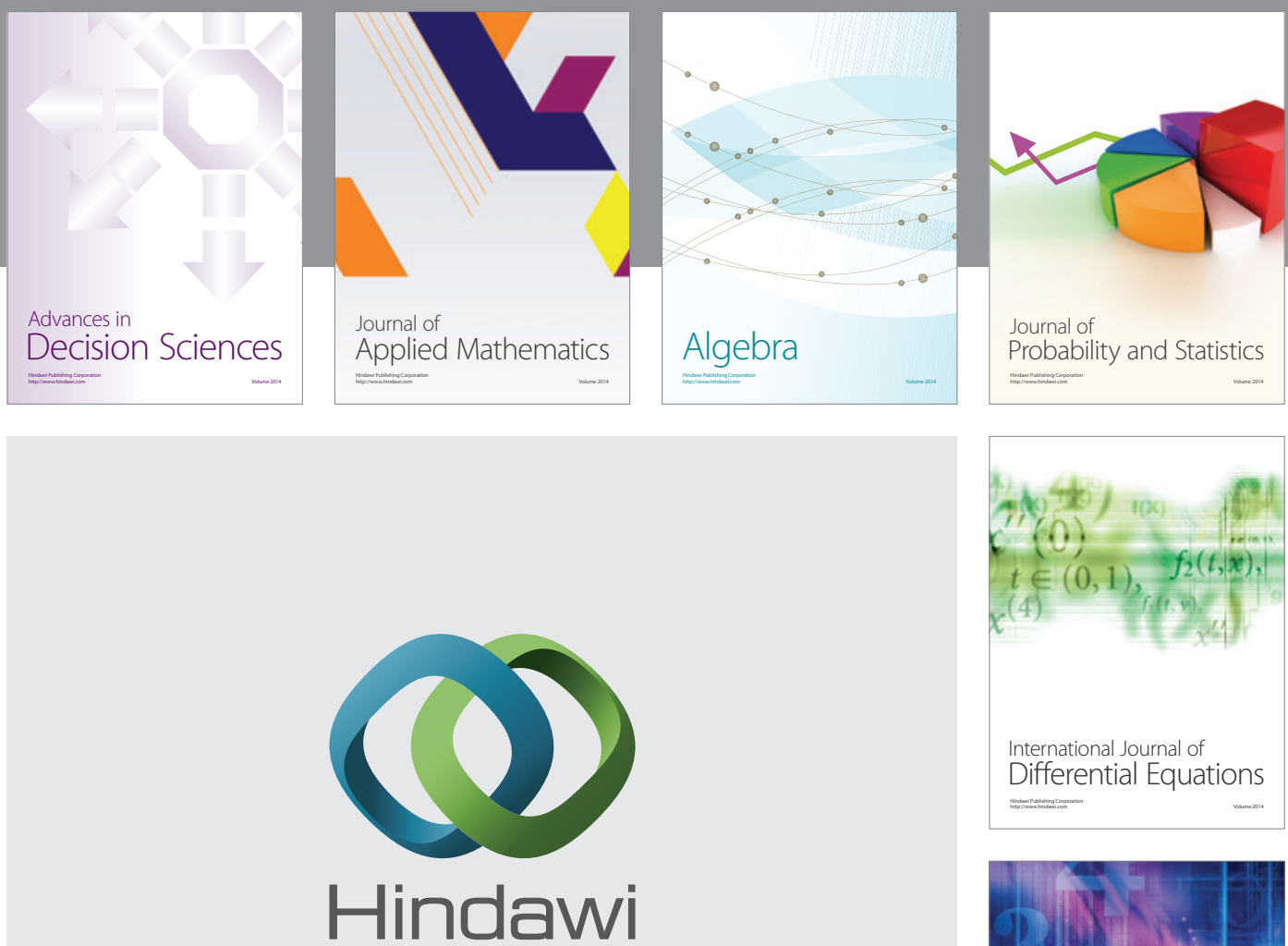

Submit your manuscripts at http://www.hindawi.com
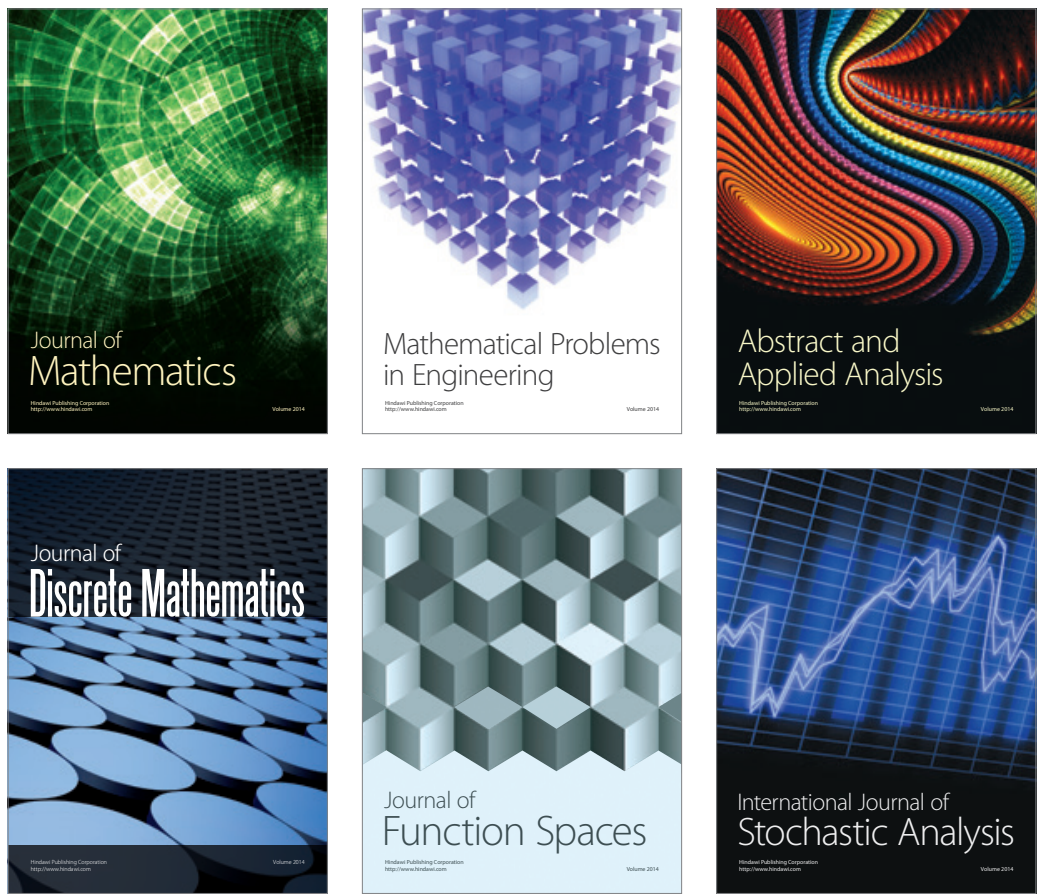

Journal of

Function Spaces

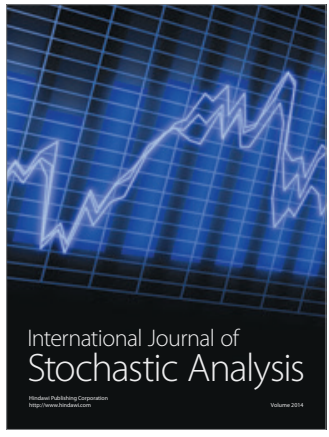

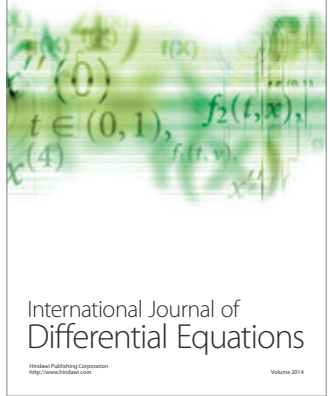
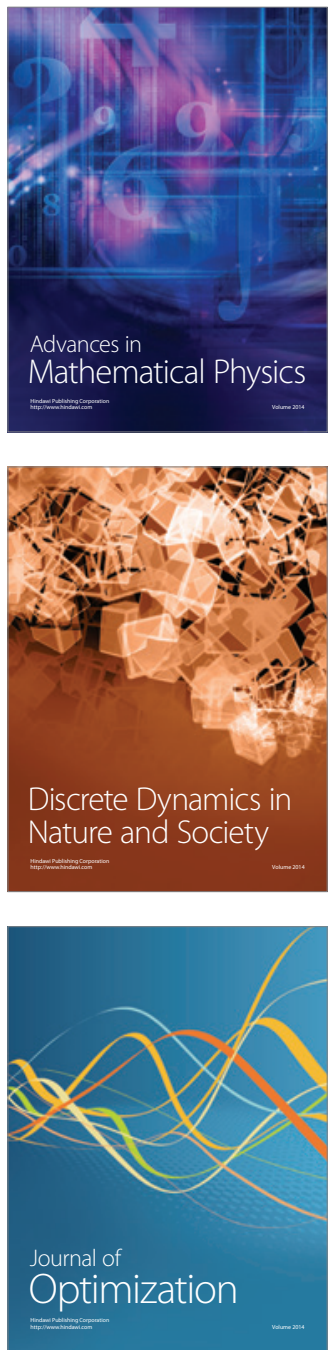